\title{
Oscips e termos de parceria com a sociedade civil: um olhar sobre o modelo de gestão por resultados do governo de Minas Gerais*
}

\author{
Alketa Peci** \\ Juliana Figale*** \\ Fábio de Oliveira**** \\ Alexandre Barragat***** \\ Conceição Souza******
}

\begin{abstract}
SumÁRIo: 1. Introdução; 2 . Administração pública e terceiro setor: uma análise das estratégias de publicização; 3. Metodologia; 4. Apresentação das Oscips; 5. Discussão dos resultados; 6 . Conclusões.

Summary: 1 . Introduction; 2. Public administration and third sector: an analysis of strategies of publicization; 3. Methodology; 4. Oscips' presentation; 5. Discussion of results; 6 . Conclusions.
\end{abstract}

Palavras-chave: Oscips; termos de parceria; choque de gestão; reformas administrativas.

KEY WORDs: Oscips; partnership contracts; 'management shock'; administrative reforms.

Este artigo apresenta os resultados de uma pesquisa que avaliou um dos componentes do choque de gestão adotado pelo governo do estado de Minas Gerais: os termos de parceria estabelecidos com as Oscips. Definido como um conjunto integrado de

\footnotetext{
* Artigo recebido em mar. e aceito em ago. 2008. A pesquisa de campo que serve de base a este artigo foi financiada com recursos da Fundação de Amparo à Pesquisa do Estado do Rio de Janeiro (Faperj).

** Professora da Escola Brasileira de Administração Pública e de Empresas (Ebape) da Fundação Getulio Vargas. Endereço: Praia de Botafogo, 190, sala 538 - CEP 22250-900, Rio de Janeiro, RJ, Brasil. E-mail: cfap@fgv.br.

*** Mestranda em administração pública da Ebape/FGV.

**** Mestrando em administração pública da Ebape/FGV.

$* * * * *$ Mestrando em administração pública da Ebape/FGV.

$* \cdots * * * *$ Mestranda em administração pública da Ebape/FGV.
} 
políticas de gestão pública orientadas para o desenvolvimento, o choque de gestão orienta-se pela gestão por resultados e é baseado numa série de instrumentos de contratualização. A pesquisa de campo realizada no decorrer do ano 2007 verificou como os responsáveis pela contratação (governo) e pela provisão (Oscips) dos serviços estabelecidos nos principais termos de parceria com o governo do estado de Minas Gerais percebem e justificam o modelo de gestão por resultados. Para responder a essa pergunta, três Oscips mineiras foram escolhidas com base na sua diversidade conceitual e operacional. Os dados foram coletados via entrevistas semi-estruturadas com representantes das Oscips e do governo mineiro e foram tratados por meio de análise de conteúdo. Os resultados da pesquisa evidenciam que a orientação por resultados já se encontra incorporada nos discursos das Oscips, mas também destacam alguns paradoxos discursivos relativos à centralidade do novo papel do Estado vis-à-vis a crítica das suas estruturas burocráticas.

Oscips and partnership terms with civil society: a view over the results-driven management model of government of the state of Minas Gerais

The central aim of this paper is to present the results of a research that evaluated one of the components of the 'management shock' adopted by the government of the state of Minas Gerais: the partnership contracts sealed with the Oscips. Defined as an integrated set of development-oriented public management policies, 'Management shock' is a results-driven management model based on several contracting practices. The field research carried out over 2007 verified how the responsible for contracting (government) and implementing (Oscips) the services established in the main partnership contracts with the government of the state of Minas Gerais understand and justify the results-driven management model. To answer this question, three Oscips from Minas Gerais were selected, considering their conceptual and operational diversity. Data were collected through semi-structured interviews with Oscips and Minas Gerais government representatives and were reviewed through content analysis. The research results show that the new management model is already incorporated in the Oscips discourses, but also highlight some discursive paradoxes on the centrality of the State's new role vis-à-vis the criticism of its bureaucratic structures.

\section{Introdução}

As ondas reformistas da administração pública brasileira não são fenômenos recentes. Ao contrário, esforços de modernização têm estado presentes desde a reforma burocrática do governo Vargas até os dias de hoje. No entanto, o escopo e o conteúdo dessas reformas mudam ao longo do tempo (Cavalcanti, 2003) e vários fatores podem explicar essa mudança. A trajetória histórica, os embates ideológicos, a imersão social e econômica do campo de administração pública são apenas alguns dos muitos a serem citados. Para alguns autores, mesmo diferentes nos seus objetivos, as reformas brasileiras apresentam 
alguns traços em comum (Nascimento, 1967). No entanto, novos esforços de modernização da administração pública buscam diferenciar-se de anteriores e nessa diferenciação reside, principalmente, seu caráter reformista.

O choque de gestão adotado pelo governo do estado de Minas Gerais, desde 2003, entra no cenário de modernização da administração pública brasileira como "conjunto integrado de políticas de gestão públicas orientadas para o desenvolvimento" (Vilhena, 2006). Sintonizando a orientação para os resultados com o ethos do desenvolvimento, o choque de gestão foi um conjunto de medidas de rápido impacto, orientado para o ajuste estrutural das contas públicas e iniciativas voltadas para a geração de um novo padrão de desenvolvimento, tendo a inovação da gestão como elemento de sustentabilidade.

Vários instrumentos gerenciais compõem o choque de gestão. Seu denominador comum é composto das relações de natureza contratual, estabelecidas não apenas entre os vários níveis de governo, mas também entre o governo, o setor privado e o terceiro setor. Acordos de resultados, parcerias público-privadas e termos de parcerias estabelecidos com Oscips são alguns exemplos desse movimento de contratualização.

Este artigo apresenta parte dos resultados de uma pesquisa de campo que analisou o choque de gestão em Minas Gerais, no que tange aos mecanismos contratuais na base da rede de governança. Especificamente, o artigo buscou responder à seguinte pergunta: como os responsáveis pela contratação e pela provisão dos serviços estabelecidos nos principais termos de parceria com o governo do Estado de Minas Gerais percebem e justificam o modelo de gestão por resultados? Em outras palavras, a pesquisa analisa as percepções dos parceiros envolvidos nos termos de parceria materializados pelas Oscips mineiras, em relação à orientação por resultados inerentes à reforma.

Foi realizada uma pesquisa de campo em três Oscips mineiras celebrantes de termos de parceria: Associação para o Desenvolvimento da Radiofusão de Minas Gerais; Instituto Hartmann Regueira; e Movimento das Donas-de-Casa. As Oscips foram escolhidas com base na diversidade conceitual e operacional. Os dados foram coletados via entrevistas semi-estruturadas com representantes das Oscips e do governo mineiro e tratados por meio da análise de conteúdo.

\section{Administração pública e terceiro setor: uma análise das estratégias de publicização}

Seja como conseqüência da crise do Estado, seja como resultado da pressão exercida pela sociedade civil num contexto de democratização, a relação do 
Estado com a sociedade civil vem sendo modificada em forma e conteúdo. O documento elaborado em 1995, como um plano de reforma do aparelho de Estado (Mare, 1995) foi uma das primeiras referências a diagnosticar as mudanças nessa relação e a qualificá-las em termos de estratégias de publicização.

As organizações sociais (OSs) foram concebidas como instrumentos responsáveis pela implementação da estratégia de publicização (Mare, 1995). No entanto, tal estratégia não encontrou eco num contexto onde os objetivos fiscais e econômicos da reforma se sobrepunham pela urgência na demanda de soluções e pela pressão de interesses mais organizados. Mesmo que as OSs criadas em nível federal tenham sido reduzidas em número, a estratégia de publicização continuou a ser materializada por meio de legislação específica, de nível federal ou estadual. Figuras jurídicas como fundações estatais, serviços sociais autônomos, são apenas algumas a serem mencionadas na institucionalização da relação Estado-sociedade.

As Oscips podem receber recursos públicos por meio de termo de parceria, um novo instrumento jurídico definido na própria Lei no 9.790/99. Antes dessa lei, os repasses se davam exclusivamente por meio de convênios, o que obrigava tanto o governo quanto as entidades parceiras a seguirem o disposto nas instruções normativas da Secretaria do Tesouro Nacional IN/STN no 01/1997 e no 03/1993. O termo de parceria é um instrumento menos rigoroso que os convênios na aplicação dos recursos recebidos do governo. Não é necessário seguir a legislação de licitações, Lei oㅗ 8.666/93, devendo a instituição publicar em 30 dias contados da assinatura do termo de parceria seu regulamento de compras e contratações. Além disso, são considerados legítimos os adiantamentos da Oscip à conta da parceria no caso de atraso nos repasses públicos e as despesas ocorridas entre o término da vigência do termo de parceria e a sua renovação (Leite, 2003).

Os novos instrumentos jurídicos acima mencionados foram responsáveis por viabilizar a estratégia de cooperação do governo com o terceiro setor e o setor privado, ao longo dos últimos anos. No entanto, eles também tornaram mais complexos os arranjos institucionais utilizados para essa finalidade, uma vez que multiplicaram os atores e as formas de relação entre eles. Daí nasce o debate contemporâneo sobre a governança, que se refere à qualidade da interação entre o governo, a sociedade civil e o setor privado (Prats I Catalá, 2006).

Por trás desse quase senso comum há, no entanto, duas grandes correntes que se opõem, no debate entre new public management (NPM) e governança. A NPM vem da iniciativa inglesa na administração de Margaret Thatcher, que buscou incorporar aos serviços públicos as práticas gerenciais da iniciativa privada. Estando a NPM tão culturalmente enraizada na cultura anglo-saxônica, não chega a surpreender que aqui seus conceitos nunca tenham sido pro- 
fundamente aplicados. Para Peci, Pieranti e Rodrigues (2007), a governança pode ser vista como conseqüência de estratégias de orientação NPM, mas se distingue também desta última pela sua orientação para a sociedade civil em vez de prioritariamente para o mercado. Um extrato das diferenças entre a NPM e a governança é reproduzido no quadro.

\section{New public management X governança}

\begin{tabular}{|c|c|c|}
\hline Conceito & New public management & Governança \\
\hline \multirow[t]{2}{*}{$\begin{array}{l}\text { Redução da } \\
\text { dicotomia público- } \\
\text { privada }\end{array}$} & $\begin{array}{l}\text { A dicotomia é considerada } \\
\text { obsoleta, por causa da } \\
\text { ineficiência do Estado }\end{array}$ & $\begin{array}{l}\text { A dicotomia é considerada obsoleta, por } \\
\text { causa da maior participação de outros } \\
\text { atores }\end{array}$ \\
\hline & $\begin{array}{l}\text { Solução proposta: importação } \\
\text { de técnicas gerenciais do setor } \\
\text { privado }\end{array}$ & $\begin{array}{l}\text { Solução proposta: o setor público deve } \\
\text { assumir um papel de liderança na } \\
\text { mobilização de redes público-privadas }\end{array}$ \\
\hline $\begin{array}{l}\text { Ênfase crescente na } \\
\text { competição }\end{array}$ & $\begin{array}{l}\text { A competição é estratégia central } \\
\text { para o aumento da eficiência da } \\
\text { gestão pública e para responder } \\
\text { melhor ao cliente }\end{array}$ & $\begin{array}{l}\text { A competição não é vista como estratégia } \\
\text { central; o foco está na mistura de } \\
\text { recursos públicos e privados, com maior } \\
\text { competição, onde for o caso }\end{array}$ \\
\hline \multirow{2}{*}{$\begin{array}{l}\text { Ênfase na gestão } \\
\text { dos resultados ao } \\
\text { invés do controle } \\
\text { dos insumos }\end{array}$} & $\begin{array}{l}\text { Foco nos resultados e crítica ao } \\
\text { controle dos insumos }\end{array}$ & $\begin{array}{l}\text { Existe dificuldade em especificar } \\
\text { os objetivos e, conseqüentemente, } \\
\text { resultados das políticas públicas }\end{array}$ \\
\hline & $\begin{array}{l}\text { Mecanismos como contratos de } \\
\text { gestão e acordos de resultados } \\
\text { são incentivados }\end{array}$ & $\begin{array}{l}\text { Mecanismos como contratos de } \\
\text { gestão ou acordos de resultados são } \\
\text { incentivados }\end{array}$ \\
\hline \multirow[t]{2}{*}{$\begin{array}{l}\text { Ênfase no papel } \\
\text { articulador do } \\
\text { Estado }\end{array}$} & \multirow{2}{*}{$\begin{array}{l}\text { O Estado deve ser capaz de } \\
\text { cortar gastos, ao mesmo tempo } \\
\text { que responde às expectativas } \\
\text { crescentes e diversificadas da } \\
\text { clientela }\end{array}$} & $\begin{array}{l}\text { O Estado deve ser capaz de aumentar as } \\
\text { coalizões com outros atores, definindo } \\
\text { prioridades e objetivos }\end{array}$ \\
\hline & & $\begin{array}{l}\text { A comunicação entre os diversos atores é } \\
\text { estimulada pela ação do Estado }\end{array}$ \\
\hline \multirow{2}{*}{$\begin{array}{l}\text { Desenho das } \\
\text { estruturas } \\
\text { organizacionais }\end{array}$} & $\begin{array}{l}\text { Estruturas governamentais } \\
\text { mínimas }\end{array}$ & \multirow{2}{*}{$\begin{array}{l}\text { Estruturas interorganizacionais, } \\
\text { acompanhadas por modificações na } \\
\text { estrutura de pessoas, procedimentos, } \\
\text { instrumentos de gestão, planejamento e } \\
\text { orçamento e transparência }\end{array}$} \\
\hline & $\begin{array}{l}\text { Diferença entre formulação e } \\
\text { execução de políticas, a partir da } \\
\text { lógica agent-principal }\end{array}$ & \\
\hline
\end{tabular}

Fonte: Peci, Pieranti e Rodrigues, 2007.

O quadro aprofunda a reflexão sobre a NPM e a governança, permitindo reconhecer padrões em uso no cenário brasileiro. A escolha entre uma das 
soluções normalmente deriva de decisões políticas do governo, da cultura e do seu contexto. Cabe verificar o modelo que melhor descreve o processo de reforma em andamento no choque de gestão mineiro.

\section{Administração pública e as Oscips no choque de gestão}

Atualmente, boa parte das experiências de publicização encontra-se em curso no nível estadual. Além de Minas Gerais, São Paulo e Pernambuco são apontados como líderes na execução de políticas públicas em parceria com a sociedade civil (Pacheco, 2006; Martins, 2007). Embora os outros estados tenham as experiências mais avançadas, notadamente com o caso da administração de hospitais na periferia de São Paulo e das escolas de Pernambuco, é o chamado choque de gestão em Minas Gerais que vem recebendo maior atenção dos meios de comunicação.

O principal vetor de adoção das parcerias com a sociedade civil tem sido o da restrição fiscal. O estado de Minas Gerais não é exceção, considerando a grave crise fiscal enfrentada pelo governo em 2003. Essa situação levou a uma ampla reforma administrativa, institucionalizada a partir da edição de um conjunto de 63 leis delegadas - editadas pelo Executivo - logo no primeiro mês e um contingenciamento de verbas para os 100 primeiros dias de governo. Foram extintas secretarias, superintendências, diretorias, unidades administrativas e cargos comissionados e iniciado um planejamento estratégico de médio e longo prazos.

O choque de gestão pode ser qualificado como uma reforma de gestão pública que estimula as relações de governança contratuais. Orientado pelo alcance de resultados, o instrumento fundamental da reforma é o contrato de gestão, no qual se registram os compromissos negociados entre as partes, incluindo metas, objetivos e impactos esperados. No caso de Minas Gerais, o contrato de gestão ganha nomes diferentes de acordo com o contratante. Se o contrato é intragoverno, como o celebrado voluntariamente entre governador e secretário, é um "acordo de resultados". Se o contratado é uma empresa privada, recebe o nome de "parceria público-privada". No caso de atendimento de uma demanda social pela execução direta de uma Oscip mineira, o instrumento recebe o nome de "termo de parceria", que é o enfoque deste artigo.

\section{A concepção do modelo e o termo de parceria}

As parcerias entre o governo e as organizações da sociedade civil de interesse público são conhecidas desde sua gestação em âmbito federal. Ocorre 
que, ao carecer de agilidade e flexibilidade na gestão do Estado (Lemos et al., 2006:131), verificou-se a necessidade de reordenar funções de caráter público junto à sociedade civil organizada. Dessa forma, emergiram parcerias que, pela obtenção de qualificações específicas, calcaram-se nos resultados efetivamente observáveis na sociedade.

Nesse contexto, a Lei Federal no 9.790/99 foi responsável por inaugurar as Oscips enquanto parceiras do Estado para a realização de tarefas de interesse público, representando o marco legal do terceiro setor. O choque de gestão, por meio da sua orientação por resultados, permitiu uma ênfase maior no relacionamento entre governo e sociedade civil organizada, a partir de uma detalhada contratualização de resultados. Dessa forma, o recurso ao instrumento das Oscips no âmbito do estado de Minas Gerais deveu-se à implementação da Lei Estadual no 14.870, de 16 de dezembro de 2003, por meio da qual instaurava-se um mecanismo para atender "a necessidade de descentralização e flexibilização do Estado e as demandas de fomento a projetos específicos do terceiro setor" (Lemos et al., 2006:131).

As Oscips mineiras instituem um novo modelo híbrido, com gestão típica de OSs e fomento com aspecto de Oscips. No que concerne à transferência de serviços relevantes do Estado para o terceiro setor, há um estreitamento com as OSs. Por sua vez, o modelo assemelha-se às Oscips federais quando da prestação dos referidos serviços por iniciativa própria ou da titularidade ordenadora da atuação do terceiro setor.

A regulamentação das Oscips estaduais foi verificada com o Decreto $\mathrm{n}^{\circ}$ 43.749, de 12 de dezembro de 2004, segundo o qual se detalhou o processo de qualificação, o termo de parceria, o processo seletivo, o acompanhamento e fiscalização e o fomento às atividades das Oscips. Dessa forma, para qualificarse como Oscip é necessário o cumprimento dos requisitos legais e a atuação em áreas de orientação social, especificadas no Manual Oscip, da Secretaria de Planejamento e Gestão (Seplag, 2004:5).

No que se refere à relação entre o Estado e as Oscips, vale salientar que o primeiro "não deixa de ser o responsável pelo serviço perante a população" (Lemos et al., 2006:134), uma vez que o segundo é apenas o executor das benfeitorias. Isso significa que a presença do terceiro setor não visa, a princípio, à diminuição do Estado. Este último passa, apenas, a focar-se no papel de formulador e fomentador da política. Cabe também a ressalva de que, com a nova legislação mineira, os servidores e os bens públicos podem ser cedidos à organização. Para tanto, procede-se a um termo de parceria, segundo o qual se materializa o vínculo criado entre as partes. É importante lembrar, nesse sentido, que a iniciativa da parceria pode surgir dos dois lados, do governo e das entidades. A figura 1 resume as relações típicas aos termos de parceria. 
Figura 1

Fluxograma típico de um termo de parceria

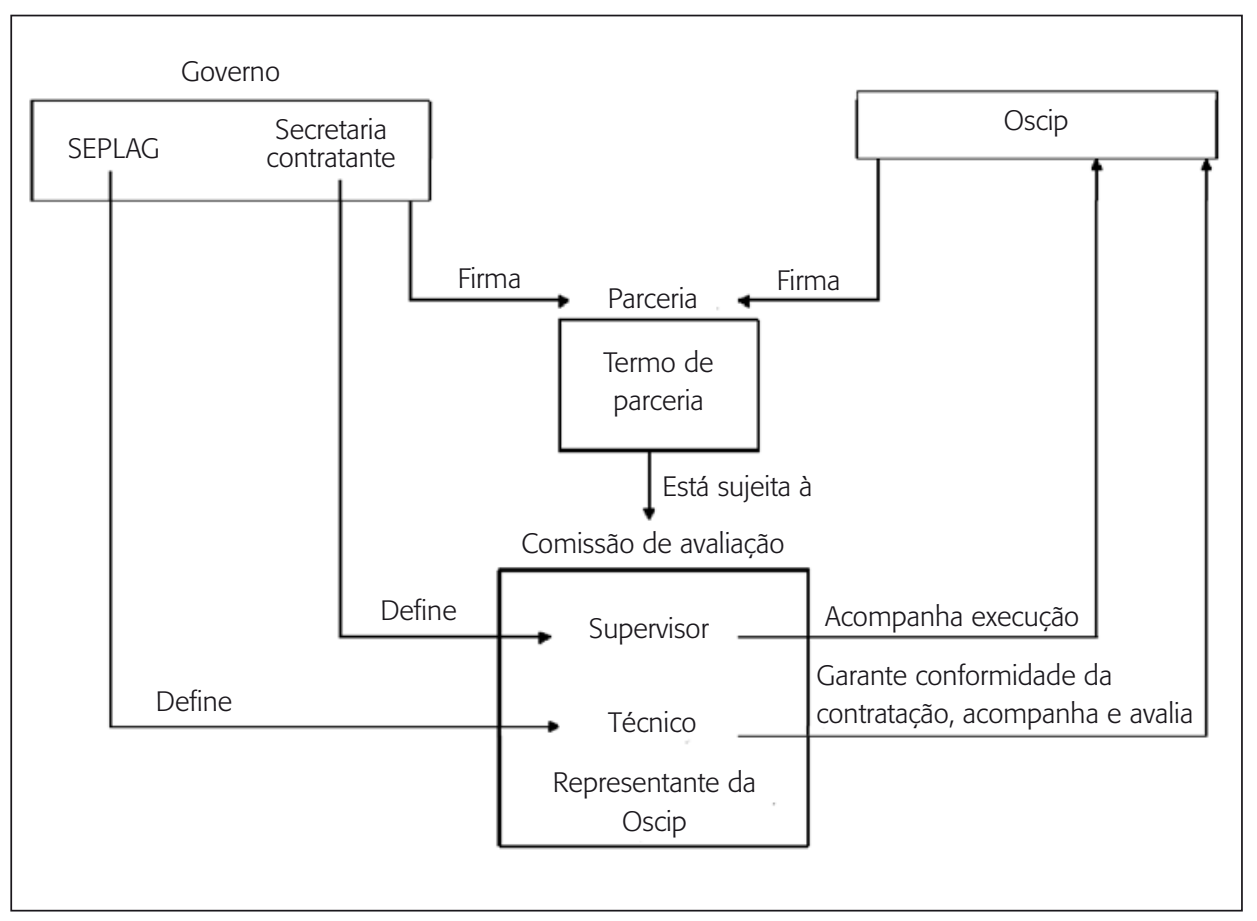

A negociação do termo de parceria com uma Oscip no estado de Minas Gerais conta com colaboração da Seplag que, por sua vez, auxilia na definição das metas a serem atendidas. O monitoramento por parte do governo às Oscips, por sua vez, se dá por meio de uma comissão, encarregada de verificar se o previsto pelo termo de parceria fixado está sendo efetivamente cumprido. No entanto, trata-se de um controle a posteriori, focando mais nos resultados do que no processo em si.

Além disso, o manual das Oscips especifica que elas serão submetidas a uma rígida fiscalização, que passa pelo Ministério Público; Tribunal de Contas do Estado de Minas Gerais; Secretaria de Estado de Planejamento e Gestão, além do órgão parceiro; Conselho de Políticas Públicas de sua área de atuação; e sociedade em geral, uma vez que qualquer cidadão poderá denunciar irregularidades cometidas pelas Oscips aos órgãos públicos citados, que deverão não somente verificar a veracidade da denúncia, mas também dar retorno ao cidadão denunciante (Manual Oscip, 2004:14).

No que se refere ao financiamento, observa-se que a transferência de recursos é feita pelo Estado, podendo a Oscip também captar recursos no merca- 
do em casos específicos. O uso irregular dos recursos públicos pode provocar desqualificação da Oscip. O Manual Oscip descreve com mais detalhes como se processa o controle em questão.

O novo modelo proposto também passa por obstáculos e apresenta suas vantagens. Lemos e colaboradores (2006:140-141) apontam para o desconhecimento dos mecanismos ideais de funcionamento do modelo. Outra desvantagem seria a resistência à mudança, o rompimento das barreiras burocráticas dificultam o enfoque nos resultados, priorizando o processo. No entanto, a preferência do novo modelo pelos resultados tem a vantagem, segundo os mesmos autores, de atribuir transparência ao planejamento, na medida em que são construídos indicadores de desempenho. Por fim, vale declarar a maior flexibilidade na gestão de recursos, permitindo agilidade na prestação de serviços.

Até o momento, o governo de Minas Gerais celebrou 14 termos de parceria, um número relativamente pequeno, quando se considera que existem 115 entidades qualificadas como Oscips. Coutinho, Bernardo e Silva (2008) analisaram três casos de Oscips mineiras que celebraram termos de parceria no âmbito do choque de gestão. Segundo os autores, ainda há um considerável desconhecimento sobre a metodologia e os mecanismos de funcionamento do modelo por parte dos próprios órgãos estatais, das Oscips e dos órgãos de controles. Como conseqüência, há receio por parte dos órgãos estatais em realizar parcerias com Oscips, pois são encontradas dificuldades e resistências da elaboração do termo de parceira à adoção de um formato de controle focado em resultados, assim como existe insegurança de ordem jurídica e cultural com relação ao modelo. Por outro lado, existe desconhecimento também por parte das Oscips. O trabalho com o Estado impõe requisitos administrativos e legais totalmente novos para essas entidades, que passam a ter que conciliar a promoção de determinado serviço social com a condição de parceira do Estado, obrigando-se a prestar contas sobre os recursos utilizados e os resultados alcançados. Por fim, o modelo demanda controle e acompanhamento constante das parcerias, tornando imperativa a necessidade de controle interno (exercido pelos próprios órgãos estatais e pela Auditoria Geral do Estado, que criou uma área específica para cuidar dos instrumentos de contratualização de resultados) e externo (exercido pelo Ministério Público e o Tribunal de Contas do Estado, os quais já solicitaram informações sobre as parcerias vigentes, mas o fizeram de maneira pontual, incompleta e confusa). Além dessas dificuldades, os autores apontam as potencialidades decorrentes do modelo, em termos de intersetorialidade, participação, transparência, accountability e responsividade do governo.

\section{Metodologia}

Foi realizada uma pesquisa de campo relativa a três termos de parceria do governo mineiro: Associação para o Desenvolvimento da Radiodifusão de 
Minas Gerais, Instituto Hartmann Regueira e o Movimento das Donas-deCasa (MDC).

São considerados critérios de seleção da amostra: o volume de recursos destinados à parceria; o tempo de contrato, a fim de se obter um conhecimento acerca de projetos que já apresentam algum tipo de resultado; e a diversidade, uma parceria de execução de projetos de duração predeterminada (quatro dos seis estão inseridos nesse contexto), outra entidade que assuma projetos sociais anteriormente providos diretamente pelo Estado (dois dos seis encontram-se nesta situação) e a terceira uma organização da sociedade civil "pura", ou seja, preexistente à atual gestão, que empregue majoritariamente trabalho voluntário e se financie no mercado. Feitas tais considerações, vale o critério da proximidade geográfica a Belo Horizonte, onde foi realizada a pesquisa de campo.

Os dados foram coletados por meio de pesquisa bibliográfica e documental, entrevistas semi-estruturadas com representantes das Oscips selecionadas no estado de Minas Gerais e da Seplag — órgão central na articulação das parcerias. Quando permitido, as entrevistas foram gravadas e, posteriormente, transcritas.

Em virtude da subjetividade na interpretação de percepções acerca dos resultados sociais dos projetos realizados, elegemos para o tratamento dos dados o método da análise de conteúdo com grade mista (Vergara, 2006) que consistiu nos seguintes passos:

v revisão da literatura de cada uma das questões explicitadas, levantando-se os primeiros dados da pesquisa, de caráter eminentemente teórico;

v trabalho de campo com entrevistas semi-estruturadas. Ao seu final, as fitas foram transcritas e os textos usados como documentos primários do software Atlas.ti;

v definição de uma grade fechada, oriunda de categorias derivadas do referencial teórico;

- leitura da transcrição de entrevistas, codificando as frases e parágrafos de acordo com a grade;

v expansão da grade anteriormente criada, como resultado do trabalho interpretativo, constituindo uma grade de análise mista;

v mapeamento gráfico das passagens codificadas, memos (idéias geradas durante o processo de interpretação) e categorias em redes relacionais, efetivamente subindo um degrau na escala de abstração e criando as categorias centrais, explicadas em suas propriedades, estratégias, causas e conseqüências por sua rede;

v finalização da análise de conteúdo, resgatando o problema de pesquisa e confrontando-o com as categorias centrais e a teoria de modo a obter as conclusões do trabalho.

A figura 2 apresenta a grade final de análise de dados. 


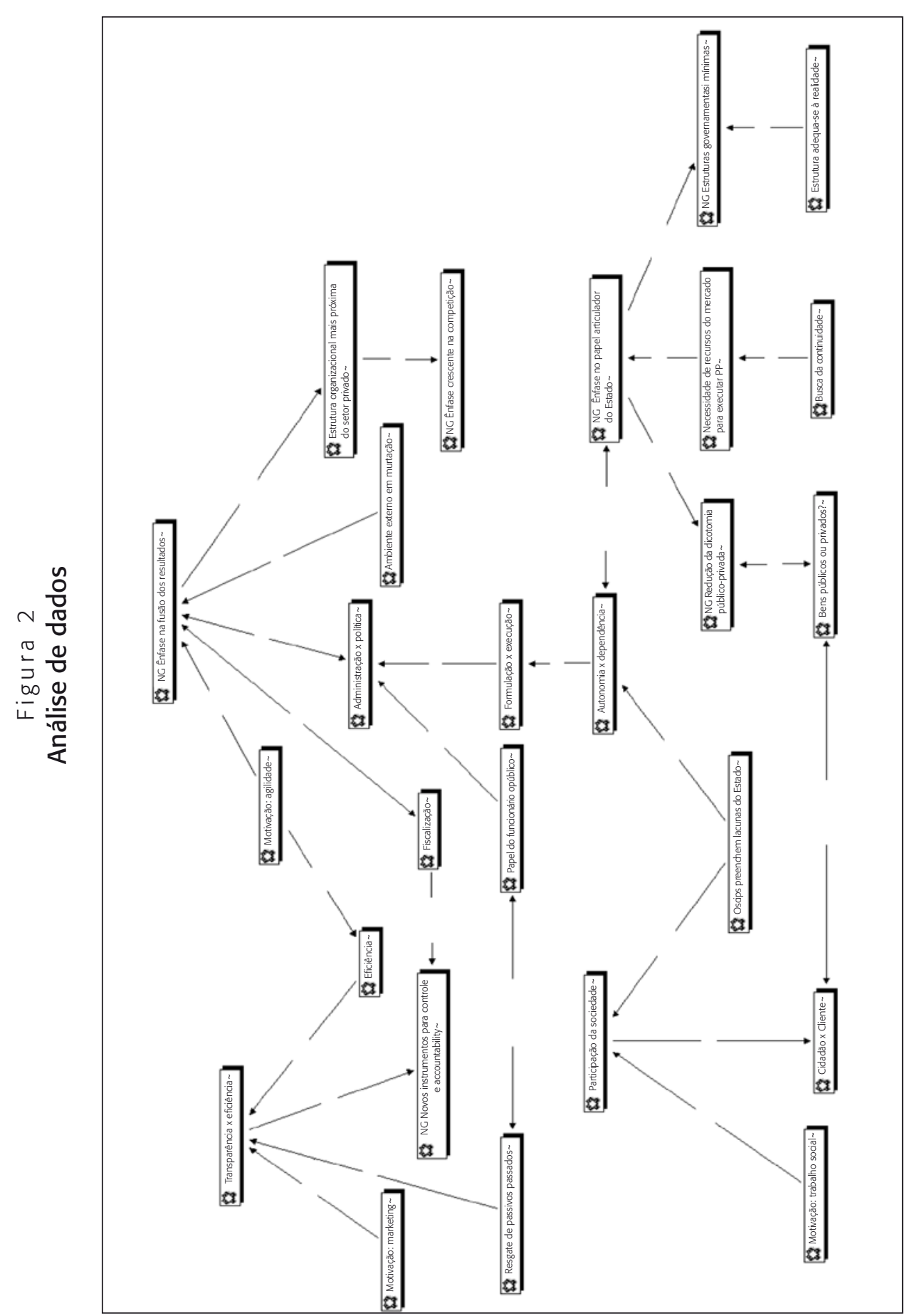

RAP - RIO DE JANEIRO 42(6): 1137-62, NOV./DEZ. 2008 


\section{Apresentação das Oscips}

Antes de apresentarmos os principais resultados da pesquisa de campo, destacaremos algumas especificidades de cada uma das Oscips analisadas no decorrer da pesquisa de campo. Boa parte dos resultados encontrados vem dessas especificidades.

\section{Associação para o Desenvolvimento da Radiodifusão de Minas Gerais (ADTV)}

A ADTV é um caso típico de Oscip criada para solucionar gargalos gerenciais. A associação foi constituída em 4 de outubro de 2005 e teve sua qualificação como Oscip publicada no Diário Oficial exatamente um mês depois, em 4 de novembro de 2005. A ADTV se tornou o braço operacional responsável pela produção de programação para a Rede Minas de televisão, com a assinatura de termo de parceria em dezembro de 2005, assumindo dessa forma atividades que anteriormente eram exercidas pela própria Rede Minas.

A Rede Minas foi criada em 1984 como uma emissora estatal de interesse público e, ao longo dos anos, desenvolveu um sério problema trabalhista. Diferentemente das demais Oscips de nossa amostra, a ADTV foi criada pelo governo mineiro, no âmbito do modelo proposto pelo choque de gestão. Com isso, absorveu pessoal que anteriormente trabalhava para a Rede Minas sob diversos contratos de trabalho, representando potencial passivo trabalhista para o Estado. Conta, ainda, com permissão de uso de bens como instalações e equipamentos de produção e transmissão pertencentes ao Estado.

Atualmente, a Rede Minas é o resultado dos trabalhos da ADTV e da Fundação TV Minas. Não há uma página institucional exclusiva da Oscip. A Fundação TV Minas conta com pequeno quadro administrativo e continua responsável pelas decisões relativas à grade de programação e, no novo modelo, por acompanhar, supervisionar e fiscalizar a execução do termo de parceria. É também sua responsabilidade repassar os recursos financeiros à ADTV. Para custear suas atividades, o termo de parceria previa o repasse à ADTV de $\mathrm{R} \$ 17.245 .199,85$, valor que foi posteriormente complementado pelos $2^{\circ} \mathrm{e}$ $4^{\circ}$ termos aditivos, respectivamente em $\mathrm{R} \$ 1.547 .508,74$ e $\mathrm{R} \$ 4.700 .000,00$, perfazendo um total contratado de $\mathrm{R} \$ 23.492 .708,59$. O termo de parceria prevê a avaliação trimestral dos resultados e a ADTV obteve conceito excelente em duas das avaliações e bom nas demais. As metas acordadas dizem respeito à qualidade, confiabilidade e disponibilidade técnica; à sistematização 
e ampliação das atividades de produção; à qualidade e diversidade da grade de programação; ao jornalismo abrangente e de qualidade; e à evolução da situação financeira. Uma constatação interessante é que não há meta relativa à audiência da programação produzida.

\section{Instituto Hartmann Regueira}

O Instituto Hartmann Regueira existe há cinco anos e atua na gestão de empreendimentos sociais. Começou como uma ONG até se transformar numa Oscip. Possui um histórico bastante produtivo em termos de obras de desenvolvimento social.

O instituto foi contatado pelo governo do estado de Minas Gerais para implementar um projeto de capacitação tecnológica junto às 3.920 escolas de referência e associáveis, localizadas em áreas de risco. A Secretaria de Estado de Educação de Minas Gerais já possuía as bases do projeto. O instituto fez, inicialmente, uma análise crítica dos instrumentos de operacionalização apresentados. A partir dessa análise, foram feitas sugestões dos modelos, ações e indicadores.

O termo de parceria, com duração de 12 meses, foi firmado entre o Instituto Hartmann Regueira e a Secretaria de Estado de Educação de Minas Gerais (SEE), com o objetivo do desenvolvimento do Projeto Escolas em Rede, a ser implementado nas escolas referência e associadas do estado de Minas Gerais, no escopo dos projetos estruturadores "Melhoria e ampliação do ensino fundamental" e "Universalização e melhoria do ensino médio". Algumas atividades que fazem parte do projeto são: inclusão digital de professores, alunos e comunidades; facilitação do gerenciamento das escolas referência e associadas; e desenvolvimento de Centro de Referência Virtual do professor. Para implementação do programa de trabalho, foi estimado o valor de $\mathrm{R} \$$ 9.542.448,68, a ser repassado à Oscip de acordo com cronograma desenvolvido. Além do termo de parceria com a Secretaria de Estado de Educação de Minas Gerais, o instituto é responsável por vários outros projetos. O Conselho e a Diretoria Executiva da Oscip são formados por voluntários, sem nenhum tipo de remuneração.

\section{Movimento das Donas-de-Casa (MDC)}

O Movimento das Donas-de-Casa surgiu em 13 de setembro de 1983, com a iniciativa da dona-de-casa Lúcia Pacífico. Desde a década de 1980, Lúcia e 
amigas formaram grupos, organizaram-se e passaram a defender a causa dos consumidores. Com o passar do tempo, o MDC firmou-se como um importante ator na defesa dos direitos do consumidor e foi responsável, juntamente com outras associações de defesa de consumidor, pela emenda popular que incluiu na Constituição Federal de 1988, a defesa dos direitos do consumidor. E assim, com um trabalho árduo e constante, o movimento ganhou legitimidade e reconhecimento na sociedade.

As principais atividades desenvolvidas pelo MDC-MG baseiam-se em serviços de assistência jurídica, orientação e atendimento ao público, além de prestação de serviços de interesses comunitários, como elaboração de pesquisa de mercado, testes comparativos, educação para o consumo e cursos diversificados para associados. É administrada por uma equipe composta de 16 membros divididos entre Conselhos Diretor, Fiscal e Consultivo.

O MDC foi a única organização participante da pesquisa de campo, responsável por procurar o governo com a proposta de se transformar numa Oscip. Isso aconteceu em 2007, após 24 anos de atividade reconhecida na defesa dos direitos do consumidor. Levando em consideração o interesse público e a legitimidade do movimento junto à sociedade, foi firmado, em setembro de 2007, o termo de parceria entre a Secretaria de Estado de Governo de Minas Gerais (Segov) e o MDC-MG, com duração de 12 meses, podendo ser prorrogado ou alterado após esse período. O objetivo do termo de parceria é a promoção da defesa dos direitos do consumidor, por meio da assistência jurídica, apoio à geração do trabalho e renda e da educação para o consumo consciente. O valor total dos recursos a serem repassados ao MDC, de acordo com cronograma estipulado é de $\mathrm{R} \$ 666.374,00$.

\section{Discussão dos resultados}

Devido às limitações de espaço, neste artigo serão analisadas de forma mais detalhada os resultados de duas categorias centrais que emergiram da análise de conteúdo: a ênfase na gestão por resultados e a ênfase no papel articulador do Estado. As outras duas categorias não serão apresentadas neste artigo.

\section{Ênfase na gestão por resultados}

Um dos principais dados que surgiu no decorrer da pesquisa de campo diz respeito à ênfase na gestão dos resultados, inerente aos termos de parceria. 
Essa orientação manifesta-se, com muita força, principalmente nos órgãos de governo como a Seplag, responsável pela concepção e implementação do modelo das Oscips. Os entrevistados afirmam “(...) tem órgãos que realmente compraram essa idéia de ter um instrumento que pactue resultados, que preze pela eficiência, que preze pelo alcance de resultados". Técnicos da Seplag, oriundos da Fundação João Pinheiro - responsável pela formação de um corpo técnico do governo mineiro que vem assumindo a liderança do choque de gestão - enxergam nos termos de parceria um dos instrumentos-chave para o modelo de estado que se almeja por meio da reforma: "O governo do estado de MG está intencionando ser um estado modelo no Brasil".

Entretanto, a ênfase na gestão por resultados também parece ter sido incorporada ao discurso das Oscips parceiras, mesmo daquelas diferenciadas com uma operação independente, como no caso do MDC, cujos entrevistados afirmam "E nós vamos ter que cumprir, tim-tim por tim-tim, todas as metas exigidas". Na ADTV, a orientação por resultados é alinhada com a preocupação com a eficiência da gestão: "Modelo Oscip é um modelo de gestão: fazer a melhor TV pública pelo menor custo (...) a ADTV é tocada sob uma relação empresarial de eficiência", afirmam os entrevistados.

A relação agent-principal (Przeworski, 1998) inerente aos termos de parceria torna mais evidentes os conflitos advindos da relação política versus administração, especificamente os embates entre técnicos e as ingerências políticas na administração (Peci, Pieranti e Rodrigues, 2007). No decorrer da pesquisa de campo, a tensão ficou mais evidente no caso da ADTV, uma Oscip criada para dar continuidade a um projeto de governo já existente, o de possuir uma TV pública. A Fundação Rede Minas, que conta com um corpo enxuto de funcionários de cargos de confiança, determina a programação a ser produzida pela ADTV que, por sua vez, concentra os técnicos. "Hoje são 350 CLT (diretos) e 100 indiretos via terceirização tradicional" com uma estrutura de diretoria "espelho da fundação", e voltada para a execução da programação definida pela FRM. Evidentemente conflitos podem surgir entre as demandas políticas e a administração da Oscip tocada por "uma pessoa que veio da iniciativa privada e era auditor". Nas palavras de um informante da ADTV, a primeira regra de resolução de conflitos é ter recurso financeiro destinado àquela demanda: "Se não tem dinheiro, não faz". Em seguida, "o diretor (FRM) tem suas demandas aceitas desde que seja cultura. Se não for cultura, entra em contato com o presidente da fundação" que deverá justificar a opção por aquela programação.

O embate política $x$ administração fica mais evidente quando os entrevistados na Oscip refletem acerca do futuro das parcerias com a troca do governo e consideram tal mudança uma possível ameaça à continuação dos contratos. 
Os conflitos advindos da dicotomia formulação versus execução de políticas públicas também foram evidenciados no decorrer da pesquisa de campo, mostrando certa dificuldade de adaptação à divisão dessas funções.

Os próprios órgãos do governo exemplificam a dificuldade, conforme aponta a respondente da Seplag: “(...) a gente tem um órgão que sempre executou as políticas públicas e de uma hora pra outra ele assume um papel de monitorar e coordenar, quer dizer de não mais executar". Em relação ao acordo de resultados, ainda que haja um contrato entre a Oscip e uma das secretarias de governo, o papel da Seplag é tido como fundamental em cada termo firmado, uma vez que esse órgão central apresenta objetivos estratégicos, como afirma uma entrevistada: "Então a Seplag entra muito pra conduzir esse processo não no sentido de direcionar o objeto do termo de parceria, mas de garantir que a metodologia seja respeitada, que acessos legais sejam observados porque o modelo dele é muito novo".

As dicotomias já analisadas tornam evidente a mudança substancial no papel desempenhado pelo governo e pelos órgãos governamentais no caso das Oscips. No entanto, a pesquisa de campo evidenciou a importância dos novos papéis desempenhados pelos funcionários públicos. Estes, embora não responsáveis diretamente pela execução das políticas públicas, são responsáveis por aspectos cruciais presentes nos novos arranjos institucionais materializados nos termos de parceria.

Além da formulação dos objetivos dos termos de parceria, acima analisados, a pesquisa evidenciou a relevância do papel de supervisor — funcionários de governo envolvidos nos termos de parceria. Segundo uma respondente da Seplag, o supervisor “(...) é um servidor destinado pelo órgão parceiro pra acompanhar a parceria. E aí acompanhar é um termo muito abrangente, mas a idéia é essa aí. O supervisor, ele é a ponte entre o órgão e a Oscip". Para ela, portanto, a figura do supervisor é central no termo da parceria firmada, podendo dirimir conflitos e identificar cedo carências de desempenho da parceria.

As atribuições do supervisor da Oscip, contudo, ainda não parecem estar plenamente divulgadas para além da Seplag, a julgar pelo depoimento de uma representante do órgão central diante da entrevista concedida por uma supervisora. As declarações são postas abaixo, respectivamente:

Eu até fiz (...) uma consulta logo que fui nomeada supervisora (...) à Seplag sobre isso. Para a Comissão de Avaliação, eles têm uma metodologia padrão para o cálculo das notas etc. Tanto é que os relatórios se você pegar o daqui ou o de outra instituição vai ver que é a mesma forma. Pra supervisão não tem. 
A falta de clareza acerca do papel de supervisor - que destaca-se pela sua relevância na gestão dos termos de parceria - evidencia a necessidade de aprimoramento gerencial do modelo.

Teoricamente, a ênfase na gestão dos resultados também influenciaria o enfoque da fiscalização: de um controle dos meios para um controle dos fins e resultados. No entanto, verificamos no campo que o modelo do choque de gestão mineiro apresentou também forte preocupação com a fiscalização dos processos internos do parceiro. As pressões que levam a essa dupla fiscalização de resultados e de processos parecem dever-se, principalmente, à presença constante das auditorias do Tribunal de Contas do Estado nas Oscips sob contrato.

Aqui novamente o papel dos técnicos do governo, especificamente da Seplag, é ressaltado. Mais especificamente o do técnico e o do supervisor da parceria. O técnico é a primeira alavanca para garantir a conformidade da contratação da Oscip, e o supervisor acompanha a execução. As atribuições do técnico são explicitadas pela respondente da Seplag: “(...) é alguém que acompanha desde o momento da negociação. Ele participa (...) de elaboração do instrumento. E depois ele propõe uma comissão de avaliação que vai trimestralmente acompanhar o planejamento de contas, o alcance de resultados deste mesmo termo de parceria". Em relação ao supervisor, a mesma entrevistada se posiciona da seguinte maneira: "então o supervisor, ele tem que estar constantemente dentro da Oscip. Ele tem que conhecer o trabalho da Oscip. Ele tem que verificar o cumprimento das metas". A justificativa, por sua vez, se refere à necessidade de criar uma cultura interna que permita à organização pública um funcionamento mais transparente: “(...) porque se você cria uma cultura de que alguém confere aquilo ali que você está fazendo, você vai ter cuidado até para organizar as informações".

Da mesma forma, outro representante da Seplag diz acreditar no formato das parcerias, desde que haja fiscalização. Seu posicionamento é justificado pela necessidade do governo mineiro de evitar os percalços já observados em nível federal:

Então diante desse problema que está ocorrendo com as transferências voluntárias do governo federal para várias entidades privadas, Oscips e ONGs, o Estado está percebendo que tem que dar uma resposta para que isso não ocorra aqui. Pra que não se questione o modelo. Está tendo problema lá por que não vai ter problema aqui? Então ele está querendo enrijecer essa questão da fiscalização até provar que realmente o instituto, ele vale pra sociedade, ele serve ao interesse público, não é? 
Assim, o respondente em questão assume que não basta repassar os recursos às Oscips parceiras. É necessário verificar se as metas estão sendo atingidas, por meio de novas abordagens de fiscalização, de natureza periódica, de surpresa.

A necessidade da fiscalização se percebe também entre as Oscips, conforme observamos no depoimento coletado no Movimento das Donas-deCasa (MDC): "eu acho que a Oscip tem que ser mesmo fiscalizada, porque a gente sabe que algumas só querem receber os recursos, desvirtuam os recursos, não é?"

Por outro lado, alguns representantes do governo envolvidos na parceria (como os membros da Fundação Rede Minas) apontam que o excesso de fiscalização pode minar a ênfase nos resultados, promovendo um retorno a uma máquina estatal lenta e pouco eficiente. Permanece pouco evidente a fronteira entre uma fiscalização, durante a vigência do termo, que garanta o cumprimento de premissas básicas e uma fiscalização cujo prosseguimento inviabilize a eficiência dos resultados acordados.

Os resultados referentes à fiscalização parecem ir na contramão da percepção dos entrevistados de que a agilidade é a principal motivação que justifica a adoção do modelo de parceria via Oscips. Representantes do governo e das Oscips consideram a agilidade um atributo do terceiro setor para alcançar resultados, uma vez que o modelo permite desvinculação parcial das burocracias inerentes à máquina estatal. A respondente da FRM, por exemplo, declara como ponto forte da pactuação do termo de parceria: "essa questão de agilidade mesmo do processo de compra. Hoje mesmo eu estava conversando com o gerente geral da supervisão que a gente está precisando de um computador. O estado demora, sei lá, três meses, se for rápido".

A importância da agilidade por parte das Oscips, por sua vez, foi destacada pelo respondente do IHR, que declarou: "então essa customização, chegar numa comunidade, eu acho que você tem que ter uma agilidade fantástica pra isso". O entrevistado da ADTV tem opinião ainda mais contundente. Para ele, um ponto forte em promover o acordo com as Oscips é a possibilidade de dar tratamento de empresa privada. Nesse contexto, agilidade, dinâmica e gestão empresarial são mudanças positivas para uma empresa que tinha cultura estatal — geralmente percebida como morosa.

As entrevistas demonstram uma crença ideológica subjacente ao instrumento das Oscips: a supremacia da gestão privada em comparação com a gestão pública. A transição para um modelo de gestão cuja estrutura organizacional se aproxima do setor privado foi ressaltada na pesquisa de campo especialmente no caso da Oscip ADTV. Mesmo a respondente da FRM — parte 
governamental responsável pela parceria — assume essa tendência como virtuosa ao afirmar sobre o dirigente da Oscip: "ele é uma pessoa que veio da iniciativa privada e ele era auditor".

No interior da própria Oscip, por sua vez, essa percepção é também muito clara. Quando questionado sobre as mudanças ocorridas na TV Minas na transição para um modelo baseado em acordo de resultados, o respondente da ADTV afirmou ter mudado a área de gestão, aproveitando o que havia de bom e mudando coisas para a iniciativa privada. Para ele, o modelo de Oscip é um modelo de gestão, segundo o qual se faz a melhor TV pública pelo menor custo. Assim, a ADTV é gerida por uma relação empresarial de eficiência. Para esse entrevistado, portanto, haver capital para desenvolver o trabalho é fundamental. Caso contrário, não se faz nada.

Dessa forma, verificamos que, ao menos no caso das Oscips utilizadas com objetivos gerenciais, prevalece o ideal de eficiência emprestado da gestão privada como motivador da mudança.

\section{Ênfase no papel articulador do Estado}

A partir do processo interpretativo de categorização e criação da rede semântica entre as categorias, emergiu dos dados da pesquisa a segunda categoria central: a ênfase no papel articulador do Estado, explicitada na figura 2.

De forma sintetizada, a categoria expressa o principal motivador que justifica as relações com organizações do terceiro setor - necessidade de contar com recursos de mercado para executar as políticas públicas. De uma forma relacionada, porém provavelmente menos virtuosa, a liberdade de amarras como a Lei de Responsabilidade Fiscal também causa esse movimento centrífugo. Nas palavras de um respondente participante do governo: "Em alguns casos é só uma estratégia, não é? Pra continuar atuando da mesma forma, eu acho. (...) Só burlar a Lei de Responsabilidade Fiscal. Com certeza, deve existir isso por aí".

A busca de recursos na iniciativa privada é comum em Oscips como IHR e MDC, cujos representantes afirmam: "Então (...) a gente chega a uma situação tal que nós temos que buscar parcerias. Seja com o Estado, seja com a iniciativa privada, seja com o Ministério Público, não é?"

Embora vista como algo desejável, a alavancagem de recursos expressivos do mercado ainda é algo precária. Em Oscips como a ADTV esse modelo ainda não é bem recebido. Os próprios representantes do governo reconhecem que são escassos os casos de sucesso na captação de recursos do mercado, limitando-se ao exemplo de uma PPP para construção de rodovia. 
Uma conseqüência natural do papel de articulador do Estado é a redução da dicotomia público-privada. O recurso aos termos de parceria implica a revisão da fronteira entre o público e o privado. As Oscips são entidades da esfera do direito privado, não fazendo parte da administração pública. $\mathrm{Na}$ maioria dos casos o contato com os cidadãos deixa de ser feito pelo servidor público e passa a ser feito pelas Oscips. Em outros, até por força dos contratos, órgãos como o TCE vão fiscalizar entidades de direito privado, parceiras do Estado. Não são poucos os dilemas envolvidos, desde a concepção até questões legais envolvendo a propriedade dos direitos sobre um determinado ativo obtido conjuntamente.

Os representantes do governo tratam a questão como algo superado: “...já não está sendo visto de uma forma assim tão negativa, não é? Porque até bem pouco tempo atrás você falar nisso era uma privatização do Estado, era uma forma de se vender, então". Ou ainda: "assim, concretamente, o fato de ser uma Oscip ou o fato da pessoa estar trabalhando lá, o jornalista, para ele pouco importa se quem está pagando o salário dele é uma Oscip ou outra instituição qualquer".

No entanto, também do ponto de vista das organizações do terceiro setor, a diluição das antigas fronteiras causa preocupações. Das Oscips que pesquisamos, o Movimento das Donas-de-Casa representa melhor esse balanço entre a desejada expansão do escopo das atividades e a preocupação com a perda de autonomia, identidade até:

através dessa parceria, eu acho que seria quase assim um braço que nós estaríamos com o governo, tá? Do governo, no caso do governo de Minas na questão de políticas sociais, de políticas públicas. (...) Isso é da maior relevância, e nós vamos desenvolver atividades, é claro, do interesse público, mas sem afetar a nossa, as nossas atividades. Nós vamos continuar a mesma coisa, está entendendo?

O papel de articulador assume grande importância na rede contratual de governança - base do choque de gestão. Na opinião de um participante, o caso de Minas Gerais concentra essa responsabilidade de articulação na Secretaria de Planejamento e Gestão: "Então a figura da Seplag no modelo de parceirização com o terceiro setor é uma figura, na minha opinião, central de coordenação do modelo, da implantação do modelo em outros órgãos".

Parece que a Seplag tem ido além do papel de articulador, assumindo uma centralidade no modelo da parceria que é apontada também como fragilidade do órgão, que não consegue "disseminar as boas práticas para outros 
órgãos". A tendência percebida pelos pesquisadores do fortalecimento da figura do supervisor de parceria pode mitigar ou reforçar esse efeito, dependendo do indivíduo escolhido, sua posição e lealdades.

Entretanto, a construção das redes público-privadas não se limita à Seplag e aos supervisores de parceria. Dentro dos órgãos contratantes e Oscips há a previsão de diferentes conselhos, em sua maioria, inativos. Nesses conselhos existe um espaço para a sociedade civil organizada e diversas esferas de governo, mas sua falta de ação faz com que os espaços vazios estejam preenchidos de forma burocrática, mais uma vez, a partir da liderança das estruturas governamentais - fonte anterior de crítica.

A tentativa de contar com estruturas governamentais mínimas deve ser vista como conseqüência do novo papel articulador do Estado. À medida que o Estado delega a execução das políticas públicas, é de se esperar que serão reduzidas também as estruturas previstas para essa finalidade. Nesse ponto, os três casos estudados apresentam diferenças. No caso do MDC, a opção do Estado foi apoiar com recursos financeiros a ampliação das atividades já desenvolvidas há vários anos pelo movimento, cobrindo uma lacuna da sua presença. A contrapartida para abrir mão da formulação pareceu ser nesse caso um rigor maior na fiscalização, como relata uma informante do MDC: "Eu acho que nós fizemos o projeto para adequar à, vamos dizer assim, deficiência do governo, não foi brincadeira (...) A auditoria vai ser mensal".

Nos outros dois casos, da ADTV e IHR, a lógica segue mais fielmente o ideário da NPM em que os formuladores não executam e há uma redução na estrutura de governo. Vale, entretanto, a ressalva de que a ADTV é, na verdade, uma criação integral da presente administração, resultado de uma cisão da estrutura da Fundação Rede Minas. O depoimento da representante da FRM é expresso a seguir: "Se você olhar o orçamento da TV Minas, vai ver que mais de $90 \%$ e nem $10 \%$, uns $10 \%$, deve ser pra, nem 10 eu acho, pra Fundação. (...) É muito pouco. É só o mínimo". Finalmente, o IHR foi contratado para executar um processo assemelhado a uma consultoria. Segundo o informante, havia uma expertise na Oscip, desenvolvida em trabalhos junto à iniciativa privada, e a Secretaria de Educação o contratou para preencher uma deficiência de conhecimento.

Tudo indica que ao mesmo tempo que o Estado reduz, via Oscips, as estruturas responsáveis para a execução das políticas, ele enfrenta uma maior demanda relativa à supervisão e fiscalização dos recursos empregados pelo Estado nos modelos.

Por fim, a busca de continuidade é vista como um avanço gerencial dos termos de parceria, uma vez que garantem maior segurança em relação aos 
desembolsos do governo. O depoimento obtido na Seplag corrobora tal afirmação:

Da gestão orçamentária. Então esse é um acerto interessante porque garante às Oscips a continuidade do projeto. Quando a gente faz um termo de parceria, quando você elabora, já tem a cotação orçamentária que vai custear e você já tem recurso previsto ali. (...) Então isso é uma garantia para a entidade que no tempo de, no período vigente do termo, o recurso dela está garantido.

Entretanto, o possível ganho gerencial perde sua vantagem quando se considera o risco político do modelo, acima analisado. De fato, a boa execução não garante a continuação de projetos:

Agora, ainda que a comissão de avaliação seja favorável à continuidade, o órgão (tipicamente a secretaria contratante) pode não ter mais recurso pra aquilo, ou ele percebeu que aquele projeto não está tendo o alcance que esperava. Então, assim, tem outros fatores que podem influenciar, mas a Seplag, ela opina nesse momento (de renovação da parceria) através da comissão de avaliação.

\section{Conclusões}

A contratualização é o principal instrumento gerencial utilizado no âmbito do choque de gestão mineiro. Entre as relações contratuais de governança que a reforma busca implementar, os termos de parceria chamam particular atenção pelo resgate da estratégia de publicização (Mare, 1995) na delegação da provisão de serviços públicos à sociedade civil organizada e pela ênfase na gestão por resultados. O modelo híbrido das Oscips mineiras resgata as vantagens gerenciais das organizações sociais, ao passo que mantém a qualificação e fomento conforme as características das Oscips federais.

Este artigo procurou perceber como os responsáveis pela contratação (governo) e provisão (Oscips) dos serviços públicos estabelecidos nos principais termos de parceria com o governo do estado de Minas Gerais percebem e justificam o modelo de gestão por resultados. Para isso, foi realizada uma pesquisa de campo com os servidores públicos responsáveis pela concepção e contratação das Oscips (Seplag), assim como com representantes de três Oscips mineiras. Essas últimas foram escolhidas com base na diversidade conceitual e operacional, representando desde modelos puros que surgiram da sociedade civil organizada (como o Movimento das Donas-de-Casa) até modelos que 
buscavam soluções gerenciais (como a Associação para o Desenvolvimento da Radiofusão de Minas Gerais).

Os resultados da pesquisa revelam que os termos de parceria analisados vão se adaptando à história e à trajetória de vida das próprias Oscips. Quando o termo de parceria entra em cena como tentativa de soluções gerenciais, o discurso enfatiza a crítica à morosidade das burocracias estatais e orienta-se pela busca de maior agilidade e flexibilidade, baseada na ideologia da superioridade da gestão privada. Ao contrário, as Oscips que já ocupavam espaços de políticas públicas caracterizados pela ausência do Estado enxergam a parceria além da solução gerencial - uma atuação sinérgica que pode melhorar os resultados da sua ação - e buscam ampliar essa parceria recorrendo também aos recursos do mercado (embora com resultados ainda marginais).

De qualquer forma, a orientação por resultados está profundamente embutida no discurso dos técnicos do governo - responsáveis pela concepção e implementação do choque de gestão - mas também no discurso dos representantes das Oscips parceiras, refletindo que uma importante mudança cultural está em curso. A pesquisa também evidenciou que a relação agentprincipal inerente aos termos de parceria faz com que conflitos inerentes à dicotomia política/administração e formulação/execução surjam com certa freqüência. Em termos gerenciais, foi identificada a importância do papel dos técnicos do governo para superar os dilemas decorrentes dessas dicotomias, assim como a necessidade de aperfeiçoar gerencialmente esses papéis.

A pesquisa também evidenciou alguns paradoxos inerentes aos discursos predominantes nos termos de parceria. Discursivamente, as Oscips surgem da crítica ao papel do Estado, ou melhor, às estruturas burocráticas que desempenham esse papel. No entanto, a centralidade do papel do Estado, mais especificamente dos técnicos do governo oriundos da Fundação João Pinheiro, chama especial atenção na pesquisa. O papel articulador evidenciado no decorrer da pesquisa não significa menos atuação governamental na prática. O Estado é responsável por convocar boa parte das parcerias, por conceber novos papéis cruciais à gestão das parcerias (como supervisor e técnico) e por adotar novos mecanismos de fiscalização de resultados. A falta de atuação dos conselhos de representação da sociedade civil nas parcerias público-privadas faz com que os espaços vazios estejam preenchidos pelas estruturas burocráticas, fonte anterior de crítica. Mais uma vez encontramos uma orientação de cima para baixo na reforma, com forte papel indutor dos técnicos do governo, como evidenciado em análises históricas das reformas brasileiras de gestão pública (Nascimento, 1967; Peci, 2005).

Esses paradoxos fazem com que o modelo das Oscips oscile entre os preceitos da new public management vis-à-vis governança. Os vieses ideológi- 
cos da reforma dão mais peso à supremacia das técnicas gerenciais do setor privado e incentivam as estruturas burocráticas mínimas. Por outro lado, o papel de liderança assumido na prática pelo setor público na mobilização dos termos de parceria, a tentativa (embora precária) de misturar recursos públicos e privados e o peso crescente dos papéis organizacionais híbridos fazem com que a governança também assuma peso crescente na operacionalização do choque de gestão.

\section{Referências bibliográficas}

BRASIL. Constituição Federal. 1988.

BRESSER-PEREIRA, Luiz Carlos; SPINK, Peter. Reforma do Estado e administração pública gerencial. 7. ed. Rio de Janeiro: FGV, 2006.

CANABRAVA, Claudia Marques et al. Sistema Único de Saúde e o terceiro setor: caracterização de entidades não hospitalares que possuem serviços em atenção básica de saúde em Belo Horizonte, Minas Gerais, Brasil. Cad. Saúde Pública, Rio de Janeiro, v. 23, n. 1, 2007. Disponível em: <www.scielo.br/scielo.php?script=sci arttext\&pid=S0102311X2007000100013\&lng=en\&nrm=iso >. Acesso em: 17 jul. 2007.

CAVALCANTI, B. S. An "equalizer" administration: managerial strategies in the public sector. 2003. Tese (Doutorado) — Virginia Polytechnic Institute and State University.

COUTINHO, Frederico M. A.; BERNARDO, Renata A.; SILVA, Felipe, A. R. Contratualização de resultados com o terceiro setor (Oscip), desafios e potencialidades: a experiência de Minas Gerais. In: CONGRESSO DE CONSAD DE GESTÃO PÚBLICA, 1. Anais... Brasília, maio 2008.

FERRAREZI, Elizabete. Saiba o que são organizações da sociedade civil de interesse público. Brasília: Agência da Educação para o Desenvolvimento, 2002.

FRANCO, A. A reforma do Estado e o terceiro setor: cinco perguntas preliminares, uma pergunta fundamental e uma nota. In: SEMINÁRIO INTERNACIONAL SOCIEDADE E A REFORMA DO ESTADO. Anais... Disponível em: <www.planejamento. gov.br/arquivos_down/seges/publicacoes/reforma/seminario/AugustoFranco. pdf $>$. Acesso em: 17 jul. 2007.

LEITE, Marco Antônio Santos. O terceiro setor e as organizações da sociedade civil de interesse público - Oscips. Assembléia Legislativa do Estado de Minas Gerais. Disponível em: <www.alemg.gov.br/bancoconhecimento/tecnico/TerSet.pdf>. Acesso em: 17 jul. 2007. 
MARE (Ministério da Administração Federal e Reforma do Estado). Plano Diretor da Reforma do Aparelho do Estado. Brasília: Presidência da República, 1995.

MARTINS, Humberto Falcão. Experiência estadual em gestão pública: qualificação e avaliação de algumas inovações. In: SEMINÁRIO DIÁLOGO BRASIL ARGENTINA SOBRE GESTÃO PÚBLICA CONTEMPORÂNEA. Anais... Rio de Janeiro, mar. 2007.

NASCIMENTO, K. T. Reflexões sobre a estratégia de reforma administrativa: a experiência brasileira. Revista de Administração Pública, 1967.

PACHECO, Regina Silvia. Brasil: avanços da contratualização de resultados no setor público. In: CONGRESO INTERNACIONAL DEL CLAD SOBRE LA REFORMA DEL ESTADO Y DE LA ADMINISTRACIÓN PÚBLICA. 11. Anales... Ciudad de Guatemala, nov. 2006. Disponível em: <www.clad.org.ve/fulltext/0055867.pdf>. Acesso em: 11 ago. 2007.

PECI, Alketa; PIERANTI, Octavio; RODRIGUES, Silvia. Governança e new public management: convergências e contradições no contexto brasileiro. In: ENANPAD. Anais... Rio de Janeiro, 2007a.

. Reforma regulatória brasileira dos anos 90 à luz do modelo de Kleber Nascimento. Revista de Administração Contemporânea, v. 11, n. 1, p. 11-30, jan./ mar. 2007b.

PICIOTTO, Robert. Putting institutional economics to work: from participation to governance. World Bank, 1995. (Discussion Paper, n. 304).

PRATS I CATALÁ, Joan. Vinte años de modernización administrativa em los países de la OCDE. Leciones aprendidas. Projeto de modernizacion del Estado. In: SEMINÁRIO INTERNACIONAL SOBRE MODERNIZACION DEL ESTADO. Anales... Buenos Aires, 2006.

PRZEWORSKI, Adam. Sobre o desenho do Estado: uma perspectiva agent $\mathrm{x}$ principal. In: BRESSER-PEREIRA, Luiz Carlos; SPINK, Peter Kevin (Orgs.). Reforma do Estado e administração pública gerencial. Rio de Janeiro: FGV, 1998.

SECRETARIA DE ESTADO DE PLANEJAMENTO E GESTÃO. Manual organização da sociedade civil de interesse público. 2004. Disponível em: <www.planejamento. mg.gov.br/choque/choque.asp>. Acesso em: 10 jul. 2007.

. Oscip. 2007. Disponível em: <www.planejamento.mg.gov.br/governo/ choque/oscip/oscip.asp>. Acesso em: 18 jul. 2007.

. Projeto fundação estatal - principais aspectos. Brasília: Ministério do Planejamento, Orçamento e Gestão, 2007. 
VERGARA, Sylvia Constant. Métodos de pesquisa em administração. 2. ed. São Paulo: Atlas, 2006.

VILHENA, Renata et al. (Orgs.). O choque de gestão em Minas Gerais: políticas da gestão pública para o desenvolvimento. Belo Horizonte: UFMG, 2006.

VIOLIN, Tarso Cabral. Terceiro setor e as parcerias com a administração pública: uma análise crítica. Belo Horizonte: Fórum, 2006. 